\title{
Physical Activity Opportunities Within the Schedule of Early Care and Education Centers
}

\author{
Stephanie Mazzucca, Derek Hales, Kelly R. Evenson, Alice Ammerman, Deborah F. Tate, Diane C. Berry, \\ and Dianne S. Ward
}

\begin{abstract}
Background: Physical activity has many benefits for young children's health and overall development, but few studies have investigated how early care and education centers allot time for physical activity, along with measured individual physical activity levels for indoor/outdoor activities during a typical day. Methods: Fifty early care and education centers in central North Carolina participated in 4 full-day observations, and 559 children aged 3-5 years within centers wore accelerometers assessing physical activity during observation days. Observation and physical activity data were linked and analyzed for associations between child activity and type of classroom activity. Results: Children averaged 51 (13) minutes per day of moderate to vigorous physical activity and 99 (18) minutes per day of light physical activity while in child care. Children averaged 6 (10) and 10 (13) minutes per day of observed outdoor and indoor daily teacher-led physical activity, respectively. Outdoor time averaged 67 (49) minutes per day, and physical activity levels were higher during outdoor time than during common indoor activities (center time, circle time, and TV time). Conclusions: Physical activity levels varied between indoor and outdoor class activities. Policy and program-related efforts to increase physical activity in preschoolers should consider these patterns to leverage opportunities to optimize physical activity within early care and education centers.
\end{abstract}

Keywords: sedentary behavior, accelerometry, pediatrics

Regular participation in physical activity and reducing sedentary time are important for young children's short- and long-term health and development, including cardiovascular health, ${ }^{1-4}$ aerobic fitness, ${ }^{5}$ healthy weight development, ${ }^{2,5-8}$ gross motor skills, ${ }^{9-12}$ and bone health. ${ }^{13-16}$ Benefits of physical activity extend to children's emotional health ${ }^{17-20}$ and cognitive development, including academic achievement. ${ }^{21-23}$ Early care and education (ECE) centers are an important setting for promoting physical activity during early childhood when lifelong habits are being formed. ${ }^{24-26}$ ECE centers are crucial for physical activity promotion, as more than 7 million US children under 5 years attend center-based child care, ${ }^{27}$ where the average child attending center-based care spends about 30 hours each week. ${ }^{28}$

With the importance of the ECE setting in promoting physical activity, national organizations have recommended amounts of physical activity (light, moderate, and vigorous) that 3 - to 5-yearold children should receive during center-based care. ${ }^{6,29,30}$ The National Association for Sport and Physical Education recommends that preschoolers attending centers full time receive at least 120 minutes of physical activity, accumulated across the entire day. National Association for Sport and Physical Education recommendations also state that 60 minutes should be structured (ie, teacher-led physical activity), at least 60 minutes should be unstructured, and daily outdoor physical activity should be provided. ${ }^{30}$ The Institute of Medicine recommends children be provided 15 minutes of physical activity per hour of time in child care and to be seated continuously for no more than 30 minutes. $^{6}$ Despite these recommendations,

Mazzucca, Hales, Ammerman, Tate, and Ward are with the Dept of Nutrition, University of North Carolina at Chapel Hill, Chapel Hill, NC. Evenson is with the Dept of Epidemiology, University of North Carolina at Chapel Hill, Chapel Hill, NC. Berry is with the School of Nursing, University of North Carolina at Chapel Hill, Chapel Hill, NC. Mazzucca (mazzucca@unc.edu) is corresponding author. physical activity levels of children in center-based care are low, ${ }^{31-36}$ and experts have called for the development of child-care-based interventions to improve physical activity behaviors. ${ }^{24}$

ECE centers can promote physical activity by allocating time in their schedules for active play and limiting time spent in sedentary activities (eg, sitting between activities), which are positively associated with children's physical activity at centers. ${ }^{37,38}$ Most classroom schedules are similar across the United States and include circle time (a class-wide, formal learning period), center time [a period of play within stations (centers) in the classroom], and outdoor play time. To develop sustainable physical activity interventions for child-care centers, it is important to understand how ECE teachers allocate time for these classroom activities and children's physical activity levels during these activities. For example, increasing the time spent outdoors is a potential strategy based on previous studies reporting higher levels of physical activity outdoors compared with indoors. ${ }^{39-41}$ However, no studies have quantified the physical activity levels during different indoor classroom activities where children spend the majority of the day. This information can identify periods of the day where children are most and least active across the day, which can be used to inform interventions, recommendations, and policies to increase physical activity of children in ECE centers.

This paper will describe physical activity patterns across the day among preschoolers attending center-based care, as well as physical activity levels associated with commonly occurring classroom activities. We hypothesize that physical activity will be highest in outdoors and that physical activity during center time will be higher than circle time. Additionally, time spent in other classroom activities, such as teacher-led physical activity, meals, and nap time, will be quantified to provide context for how children spend their child-care day. Last, potential correlates of physical activity within classroom activities will be examined to identify modifiable factors that can be addressed within interventions or 
nonmodifiable factors that could facilitate targeting or tailoring of interventions.

\section{Methods}

\section{Data Collection Procedures}

Data for this study were collected within an effort to develop the Environment and Policy Assessment and Observation-Self-Report (EPAO-SR), a comprehensive measure of the ECE nutrition and physical activity environment completed by center staff, ${ }^{42}$ based on the observer-implemented EPAO. ${ }^{43}$ Data collection protocols for this study have been described elsewhere. ${ }^{42}$ Briefly, a convenience sample of 50 ECE centers participated in a 4-day assessment of the physical activity environment of classrooms for 3- to 5-year-olds and the physical activity behaviors of children in those classrooms. Observation days captured the entire day for most children in the class-beginning with the first meal or when the child-care day formally began, whichever came first, and ending when the majority of children left the center. Centers were recruited from Wake, Durham, Orange, Chatham, Alamance, and Guilford counties in North Carolina. Centers were identified through the North Carolina Division of Child Development and Early Education database (http://ncchildcaresearch.dhhs.state.nc.us/search.asp?lang=English) and were invited through letters and telephone calls. Eligible centers had at least a 2-star rating on North Carolina's quality rating and improvement system (lowest 1-star scale to highest 5-star scale). This system rates the quality of the physical spaces, programming, and staff education across all domains of early child education (ie, not specific to physical activity) and serves as a global indicator of center quality. Data were collected between August 2008 and April 2009. All methods were reviewed and approved by the University of North Carolina Institutional Review Board. Center directors and parents of children wearing accelerometers provided written informed consent prior to data collection.

\section{ECE Center Physical Activity Environment}

The physical activity environment of ECE centers was measured using the EPAO, which is divided into (1) a day-long observation evaluating provisions and practices occurring during the observed day and (2) a document review of the center's physical activity policies. Outcomes from the EPAO provide a measure of physical activity environmental characteristics of a child-care center, and the instrument has been used widely to assess physical activity environments in ECE settings. ${ }^{37,44-49}$

The observation uses a time-use diary method, documenting activities chronologically. Six classroom activities representing the major groupings of classroom activities in ECE centers (ie, outdoor play time, center time, circle time, TV time, meals, and nap time) were observed according to the time that the activity started and ended. Center time generally consisted of stations around the classroom through which children rotate, such as blocks/manipulative play, dramatic play where children dress up and engage in imaginative play, and arts and crafts projects. Circle time activities included good morning and welcome songs, discussion of the calendar, and sometimes a book read by the teacher. Other activities (eg, teacher-led physical activity and seated time) that were either less frequent or were not mutually exclusive from the 6 major categories were documented as minutes per occasion. The EPAO also documents weather- and environment-related factors used as potential correlates in this study. Temperature, precipitation, and humidity were observed with portable weather stations. Observers completed an audit of variety and use of portable play equipment (indoor or outdoor); fixed outdoor play equipment; and natural environment features (eg, trees providing shade, open, grassy areas). Three research staff members were trained and certified against a gold-standard observer to conduct the observation.

\section{Measurement of Correlates}

Center directors $(\mathrm{N}=50)$ reported center-level demographics including star rating (2-5), monthly tuition fees, and number of children attending the center. Teachers $(\mathrm{N}=124)$ reported demographic and health-related characteristics, including years of ECE teacher experience; prior training on physical activity (within $1 \mathrm{y}$ prior, $>1$ y ago, and never); weight (pounds); and height (feet and inches). Weight and height were converted to kilograms and meters, respectively, and used to calculate body mass index (kilograms per meter squared). Parents of children wearing accelerometers reported child age (years) and gender.

\section{Child Physical Activity}

Child physical activity during child care was assessed during the 4-day assessment period using ActiGraph GT1M (Pensacola, FL) accelerometers. Parents of all children in observation classrooms were invited to allow child participation. Data were collected in 15second epochs to account for the sporadic nature of young children's physical activity. The ActiLife software (Pensacola, FL) was used to obtain epoch-level data files for processing in SAS v9.2 (SAS Inc, Cary, NC). Wear and nonwear periods were identified using dates and times logged by research staff members and by applying the National Health and Nutrition Examination Survey nonwear algorithm. ${ }^{50}$ Nonwear periods were defined as intervals of at least 60 consecutive minutes of zero activity intensity counts, allowing for 1-2 minutes of counts between 0 and 100 . SAS macros were used to classify data into sedentary behavior $(<25$ counts/15 s), light physical activity ( $25-419$ counts/15 s), and moderate to vigorous physical activity (MVPA; $\geq 420$ counts/15 s) using accelerometer cut points developed by Pate et al. ${ }^{51}$ Data were summarized at the day level for total minutes of sedentary behavior and physical activity as well as minutes per hour to account for differences in total observation hours. Average counts per minute were also computed to provide an intensity-weighted overall physical activity outcome. In sensitivity analyses, cut points developed by Evenson et $\mathrm{al}^{52}$ were used to calculate alternate estimates of children's physical activity and sedentary behavior.

\section{Data Analysis}

EPAO observation and accelerometer data summarized at the day level were used to calculate means and standard deviations for overall time spent in different classroom activities and for time spent across the day in sedentary behavior and physical activity (light and MVPA). SAS macros were used to link EPAO observation and 5-minute-level accelerometer data. Overall start and stop times for the observation day were used to restrict accelerometer data to that matching EPAO data. Accelerometer data summarized in 5-minute increments were coded as occurring within one of the 6 major observation categories or coded as uncategorized time based on the time stamps for each category.

Total minutes of sedentary behavior and physical activity (light and MVPA) and average counts per minute within each EPAO classroom activity category were computed to obtain a 
category-specific sedentary or physical activity estimate. Minute per hour estimates of sedentary behavior and physical activity were calculated specific to each category using the total time observed within the EPAO, to account for differences in the amount of time spent in each EPAO category. Center-level estimates were calculated as the average of all children and observation days within a center. Differences in sedentary and physical activity estimates by classroom activity category (ie, outdoors, center time, circle time, and TV time) were assessed using analysis of variances in SAS 9.4. Four 1-way analysis of variances were used to test differences in each sedentary or physical activity outcome (ie, sedentary behavior, light physical activity, and MVPA minutes per hour, and counts per minute), accounting for the amount of time spent in each classroom activity.

Potential correlates of MVPA and sedentary time were examined separately for each classroom activity type. Based on existing literature, sociodemographic and health-related correlates included child age, child gender, monthly tuition fees (proxy for family income), center star rating, size of center, teacher body mass index, years of teacher experience, and teacher training on physical activity. Weather-related covariates included temperature, precipitation, and humidity for the observation day. Physical environment correlates included portable play equipment variety and use, calculated from the EPAO as the sum of equipment types available and used. For outdoor time, summary scores for natural elements and fixed portable play equipment variety and use were examined. A backward elimination strategy was used to identify correlates that were significantly associated with either sedentary behavior or MVPA. All potential correlates were included in initial models, from which correlates associated with sedentary behavior or MVPA with a $P$-value of .2 or lower were retained in subsequent models. Correlates not significantly correlated with sedentary behavior or physical activity outcomes at $P<.05$ level were removed individually until remaining correlates were statistically significantly associated with accelerometer outcomes.

To provide a visual illustration of the physical activity variations across the child-care day, counts per minute estimates were plotted and overlaid with corresponding EPAO categories for 3 days. The days were randomly chosen based on total minutes per day of MVPA. To avoid excessively low and high days but capture days with distinctly different amounts of MVPA, 2 days were chosen from the fourth quintile for MVPA minutes and 1 day from the second quintile. The temporal plots of physical activity by time show different ways children accumulate physical activity in ECE centers.

\section{Results}

\section{Sample Characteristics}

From the original 50 centers, 49 were used for this study; 1 was excluded because only 1 child wore an accelerometer. An average of 11 (6) children per center wore accelerometers, for a total of 559 children. Of the 3-to 5-year-olds attending participating centers, about half $(57 \%)$ were non-Hispanic white, a third (31\%) were non-Hispanic black, and $8 \%$ were Hispanic (Table 1). Classroom teachers were on average 37 years old and had been a teacher for about 10 years. Half of teachers had at least a college degree, and nearly half had participated in physical activity training within the preceding year.

\section{Time Spent in Classroom Activities}

Forty-eight centers were observed for 4 days, and 1 center was observed for 3 days, for a total of 195 observation days. Classrooms
Table 1 Characteristics of Participating Centers, Teachers, and Children

\begin{tabular}{|c|c|}
\hline & Centers $(N=49)$ \\
\hline \multicolumn{2}{|c|}{ Race/ethnicity of all 3- to 5-year-olds, $\%$} \\
\hline Non-Hispanic white & 57 \\
\hline Non-Hispanic black & 31 \\
\hline Hispanic & 8 \\
\hline Other & 4 \\
\hline Mean weekly tuition fees (SD) & $163(30)$ \\
\hline \multicolumn{2}{|l|}{ Star rating, ${ }^{\text {a }} \%$} \\
\hline 2 & 6 \\
\hline 3 & 35 \\
\hline 4 & 29 \\
\hline \multirow[t]{2}{*}{5} & 31 \\
\hline & Teachers $(N=123)$ \\
\hline Mean years as a teacher (SD) & $10(8)$ \\
\hline Mean age in years $(\mathrm{SD})$ & $37(12)$ \\
\hline Female, $\%$ & 100 \\
\hline \multicolumn{2}{|l|}{ Highest level of education, $\%$} \\
\hline High school or lower & 10 \\
\hline Some college & 39 \\
\hline College degree & 47 \\
\hline Graduate degree & 3 \\
\hline Missing & 1 \\
\hline \multicolumn{2}{|c|}{ Prior training on physical activity, $\%$} \\
\hline Never & 36 \\
\hline$<1 \mathrm{y}$ ago & 20 \\
\hline $1 \mathrm{y}$ ago or less & 44 \\
\hline \multicolumn{2}{|l|}{ BMI category, \% } \\
\hline Underweight or normal $(<25)$ & 42 \\
\hline Overweight or obese $(\geq 25)$ & 58 \\
\hline \multicolumn{2}{|l|}{ Race/ethnicity, \% } \\
\hline Non-Hispanic white & 53 \\
\hline Non-Hispanic black & 39 \\
\hline Hispanic & 2 \\
\hline \multirow[t]{2}{*}{ Other } & 6 \\
\hline & Children $(\mathrm{N}=558)^{\mathrm{c}}$ \\
\hline Female, $\%$ & 50 \\
\hline
\end{tabular}

Abbreviation: BMI, body mass index.

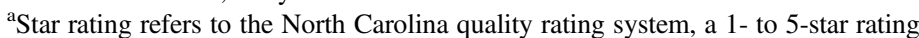
system encompassing the program's standards and education of early care and education staff. Only centers with a star rating of at least 2 were included in this study. Percentages sum to $101 \%$ due to rounding.

${ }^{\mathrm{b}}$ Teachers reported whether they had received training on physical activity with the following question: "Have you ever received training in physical activity for young children (eg, continuing education workshop or college class for credit) or training on a specific physical activity curriculum?" with response options of yes, within the past 12 months; yes, more than 12 months ago; no, but I'm attending a training in the next 6 months; or no.

${ }^{\mathrm{c}}$ Only children who wore accelerometers during the assessment visit.

were observed for about $81 / 2$ hours each day (Figure 1). Children spent on average of 67 (49) minutes each day in outdoor play, with about 7 (10) minutes of that as teacher-led physical activity. Children spent an average of 188 (13) minutes indoors each day. 


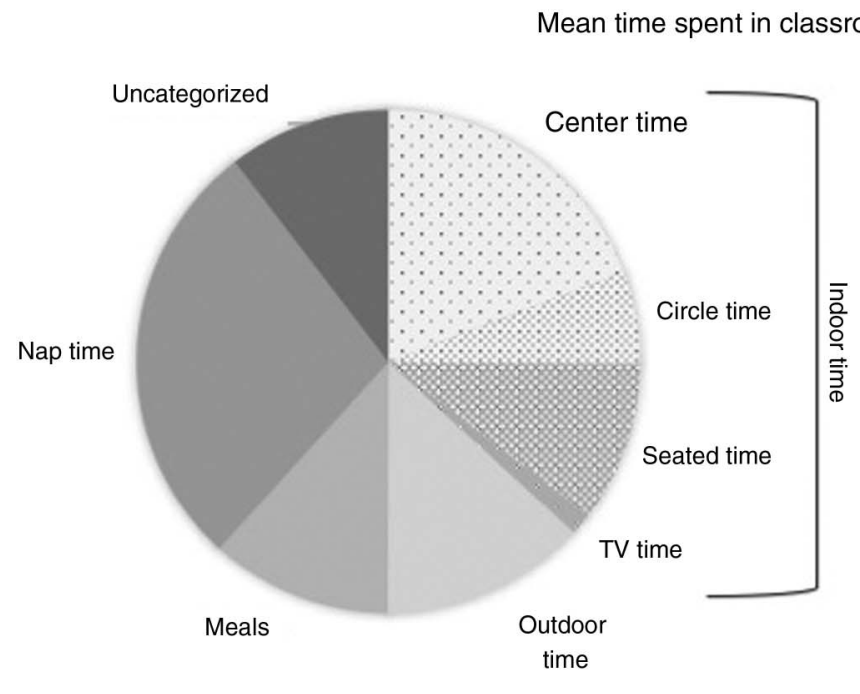

\begin{tabular}{|c|c|c|}
\hline \multirow{13}{*}{ 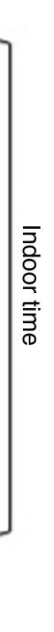 } & & $\begin{array}{c}\text { Minutes per day, } \\
\text { mean (SD) }\end{array}$ \\
\hline & Total observed time & $509.4(52.4)$ \\
\hline & Outdoor time & $67.2(49.2)$ \\
\hline & Outdoor teacher-led PA & $6.5(9.9)$ \\
\hline & Indoor time & $187.6(62.5)$ \\
\hline & Center time & $97.7(58.7)$ \\
\hline & Circle time & $30.2(18.6)$ \\
\hline & Seated time & $52.6(35.6)$ \\
\hline & TV time & $7.2(19.8)$ \\
\hline & Indoor teacher-led PA & $9.8(13.2)$ \\
\hline & Meals & $59.5(16.6)$ \\
\hline & Nap time & $142.0(28.1)$ \\
\hline & Uncategorized time ${ }^{b}$ & $53.1(35.8)$ \\
\hline
\end{tabular}

Figure 1 - Mean time spent in classroom activities in the child-care setting. Average time per day spent in each observed classroom activity is shown together in the pie chart on the left. On the right, means and SDs for classroom activities are observed. PA indicates physical activity. ${ }^{a}$ Indoor teacher-led PA is not mutually exclusive of the other indoor time categories and does not contribute to the indoor time total. ${ }^{\mathrm{b}}$ Uncategorized time did not fall within one of the prespecified observation categories, mainly including transitions between classroom activities.

During this time, children spent about 10 (13) minutes in teacherled physical activity. About 98 (59) minutes were allotted for center time, usually as 2 sessions, morning and afternoon. Children spent about 30 (19) minutes in circle time each day, usually once per day. Seated time, defined as time outside of the other prespecified categories (eg, circle time, meals, nap time) when the majority of children were required to be seated for at least 2 minutes, averaged 53 (36) minutes each day. TV time was observed for 7 (20) minutes on average but observed infrequently. Only $16 \%$ of observation days had any TV time.

\section{Physical Activity by Classroom Activity Type}

Children accumulated an average of 51 (13) minutes of MVPA, 99 (18) minutes of light physical activity, and 296 (62) minutes of sedentary behavior daily. Children accumulated the most MVPA during outdoor time [21 (12) min] versus other classroom activities, with circle time and TV time each averaging about 3 (2) minutes of MVPA each (Figure 2). Minute per hour estimates of sedentary behavior and physical activity by classroom activity indicate that the relative amount of time in sedentary behavior was lower for outdoor time $(24 \mathrm{~min} / \mathrm{h})$ and center time $(35 \mathrm{~min} / \mathrm{h})$ compared with circle time and TV time (41 and $47 \mathrm{~min} / \mathrm{h}$, respectively; Table 2 ). The time spent in MVPA was also higher for outdoor time and center time (16 and 8 $\mathrm{min} / \mathrm{h}$, respectively) than other classroom activity categories.

Analysis of variances showed significant differences in all sedentary behavior and physical activity outcomes by classroom activity types (Table 2; all $P \mathrm{~s}<.0001$ ). Pairwise comparisons adjusted for multiple comparisons indicated that estimates during circle time and TV time were not statistically different from each other. All other pairwise comparisons between minutes per hour of sedentary behavior, light physical activity, and MVPA for the 4 classroom activities were significant $(P<.0001$; data not shown).

\section{Correlates of Physical Activity}

Eight models were fit for the 4 classroom activity types and included final sets of correlate exposures and either sedentary behavior or MVPA minutes per hour as the outcome. Several factors were associated with sedentary behavior and physical activity levels during observed classroom activities (data not shown). During outside time, average child age $(\beta=3.2$, $P=.04)$ and teachers having more than 10 years of experience $(\beta=3.0, P=.03$ ) were positively associated with MVPA (minutes per hour). For center time, center star rating was negatively associated with MVPA (minutes per hour; $\beta=-0.7, P=.01$ ), perhaps because centers with a higher rating focus center time on more traditional, less active educational objectives. Weather-related factors, such as percent humidity $(\beta=0.2, P=.03)$; precipitation $(\beta=-5.4, P=.01)$; and average temperatures above $60^{\circ} \mathrm{C}(\beta=-3.8$, $P=.03$ ), were associated with sedentary behavior (minutes per hour) during circle time. No correlates were identified for outdoor time or center time sedentary behavior or for circle time MVPA. Similar associations were found in the sensitivity analysis using the alternative accelerometer cut points from Evenson et al. ${ }^{52}$

\section{Physical Activity Levels Across the Day}

To understand variations in physical activity across the entire child-care day, Figure 3 shows physical activity throughout the day for 3 days from different centers, using average counts per minute plotted by time. Graphs are overlaid with the observation data on classroom activity type. These were chosen to be representative of the sample, that is, not on the extremes of the distribution, but distinct enough to illustrate differences in "more" and "less" active days at child care. Center A (Figure 3A; average 305 counts per minute) represents a less active day, whereas center $\mathrm{B}$ (Figure 3B; average 782 counts per minute) and center C (Figure 3C; average 647 counts per minute) represent different patterns of more active days. From these graphs in Figure 3, several physical activity patterns are noted.

Across these 3 days, mornings are generally more active than afternoons. The highest peaks of physical activity most often occur during outdoor time, except in center $\mathrm{C}$, which may have replaced outdoor time that day with indoor circle time in the morning. This classroom did not go outside that morning despite 


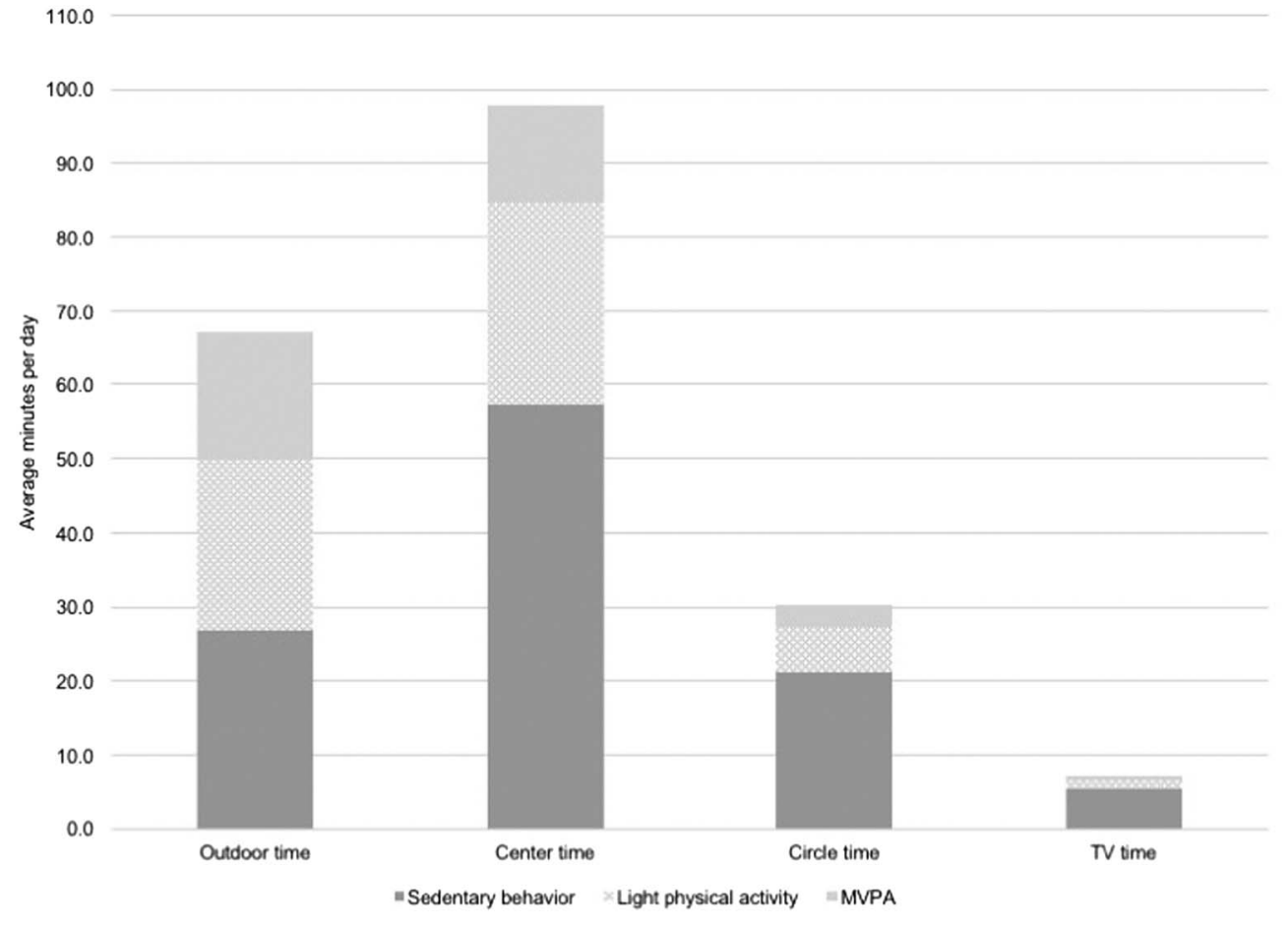

Figure 2 - Time in physical activity intensity by classroom activity type during the child-care day. Time spent (minutes per day) at different accelerometer-measured sedentary behavior, light physical activity, and MVPA are plotted for the 4 commonly occurring classroom activities. MVPA indicates moderate to vigorous physical activity.

Table 2 Physical Activity and Sedentary Behavior Estimates by Classroom Activity Type During the Child-Care Day

\begin{tabular}{|c|c|c|c|c|c|c|}
\hline & Overall $^{a}$ & Outdoor time & Center time & Circle time & TV time & \\
\hline & Mean (SD) & Mean (SD) & Mean (SD) & Mean (SD) & Mean (SD) & $P$-value ${ }^{b}$ \\
\hline Average counts per minute & $568.8(104.7)$ & $1204.8(361.3)$ & $656.8(175.0)$ & $499.6(197.9)$ & $352.7(218.2)$ & $<.0001$ \\
\hline \multicolumn{7}{|l|}{ Minutes per hour } \\
\hline Sedentary behavior & $38.1(33.2)$ & $23.5(6.1)$ & $34.7(4.2)$ & $41.4(4.9)$ & $46.7(6.2)$ & $<.0001$ \\
\hline Light physical activity & $11.4(1.5)$ & $20.9(2.8)$ & $17.2(2.3)$ & $12.8(2.9)$ & $9.1(4.0)$ & $<.0001$ \\
\hline MVPA & $10.5(1.5)$ & 15.7 (4.7) & $8.1(2.3)$ & $5.8(2.5)$ & $4.3(2.6)$ & $<.0001$ \\
\hline
\end{tabular}

Abbreviation: MVPA, moderate to vigorous physical activity.

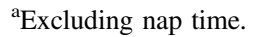

${ }^{\mathrm{b}} P$-values from analysis of variances testing group mean differences in sedentary behavior or physical activity levels (average counts per minute, sedentary behavior minutes per hour, light physical activity minutes per hour, or MVPA minutes per hour) by the 4 classroom activity types.

good weather; however, this teacher was still able to integrate intense physical activity indoors. The sharp peaks for outdoor time in centers $\mathrm{A}$ and $\mathrm{C}$ and morning circle time in center $\mathrm{C}$ also demonstrate that children are most active at the beginning of these activities, then becoming less active as the activity progresses. Overall, these graphs show the temporal sequence of physical activity and how children accumulate physical activity across the child-care day.

\section{Discussion}

This study examined the time allocated to classroom activities and physical activity across the day of preschoolers attending centerbased care, including physical activity levels during commonly occurring classroom activities. Key findings from this study are significantly higher levels of MVPA and lower levels of sedentary behavior during outdoor play, as in other studies, and during center time, a novel finding, compared with other indoor activities. This highlights important differences in the way classroom teachers use their schedules and opportunities for increasing physical activity across the day in ECE centers.

Within this sample, teachers allocated an average of 67 minutes per day of time for outdoor play, notably higher than a recent study by Tandon and Saelens, ${ }^{41}$ who observed 33 minutes of outdoor time in child-care centers in Seattle, Washington, DC. The teacherled physical activity estimates ( $10 \mathrm{~min}$ indoors and $6 \mathrm{~min}$ outdoors) from our study are also higher than those in the Tandon and Saelens' study (8.4 and 0.4 min, respectively), but lower than those found by LaRowe et al. ${ }^{53}$ These differences could be due to sampling differences, geographical differences, or characteristics 

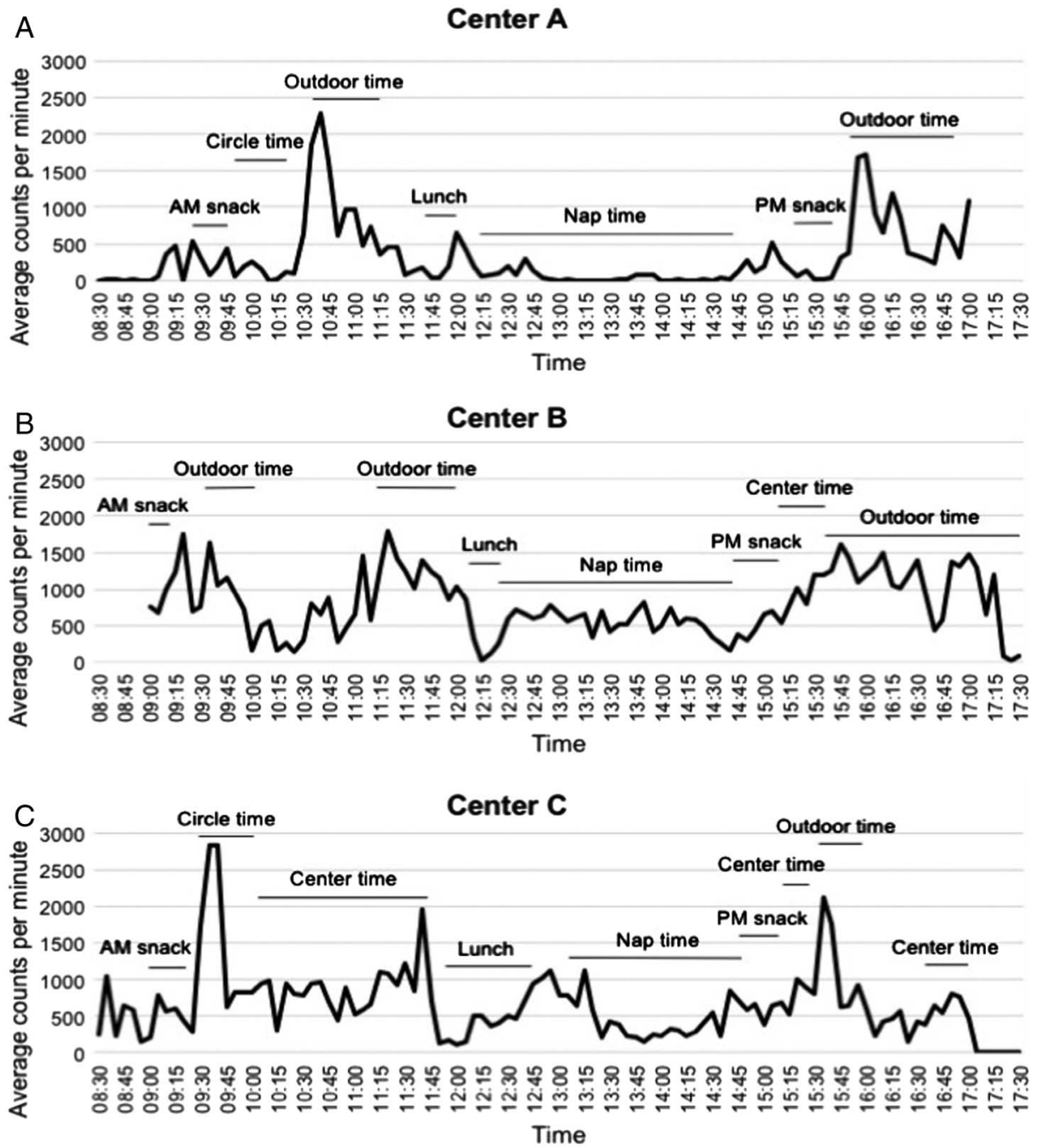

Figure $3-(\mathrm{A})-(\mathrm{C})$ Physical activity across the day in 3 centers. These graphs depict the time course of accelerometer-measured physical activity across the day at 3 centers, overlaid with data from observations conducted by research staff indicating the classroom activity taking place at the corresponding time.

of the teachers. Similar amounts of total MVPA were observed in this study $(51 \mathrm{~min} / \mathrm{d}$ and $11 \mathrm{~min} / \mathrm{h})$ compared with estimates of 55 minutes $^{41}$ and 7 minutes per hour ${ }^{39,40}$ from other studies.

Several correlates were found that were specific to outdoor MVPA or center MVPA time, but no correlates were identified for MVPA during circle time. Within center time, the finding that the center's star rating was negatively associated with MVPA could be because centers with a higher rating focus center time on more traditional, less active educational objectives. The North Carolina star rating system does not have a specific component related to physical activity, but instead, it is more of a global indicator of the quality of the center. Correlates for only one of the 4 classroom activity periods (circle time) were identified for sedentary behavior. Other studies have identified important child- and center-level correlates of overall physical activity, including natural features, ${ }^{54,55}$ fixed play equipment, ${ }^{46}$ portable play equipment, ${ }^{37,46}$ and playground density. ${ }^{56}$ The present sample may have been too homogenous in both correlates and sedentary and physical activity levels within each classroom activity; future work is needed to expand upon this.

Of these 49 centers, $32(65 \%)$ met the Institute of Medicine recommendation for 15 minutes of nonsedentary time per hour, compared with $42 \%-50 \%$ of children in a study by Pate et al..$^{34}$ Children accumulated an average of 99 minutes of light physical activity and 51 minutes of MVPA, but children were only offered an average of 16 minutes of observed teacher-led physical activity. Most centers $(n=41)$ met the National Association for Sport and Physical Education recommendation for 120 minutes of total physical activity for all observation days, but no center met the recommendation for offering 60 minutes of teacher-led physical activity on all observation days.

The results from this study can inform intervention development, specifically the times of day where there is most potential for adding in physical activity or reducing sedentary behavior based on time spent in different classroom activities and sedentary behavior and physical activity levels of children during those classroom activities. Opportunities exist for increasing physical activity both indoors and outdoors. Because children accumulate most of their MVPA from outdoor play, it is important to optimize outdoor time to be as active as possible. Children may need additional prompts to be active, as their physical activity levels decrease over time during outdoor play. ${ }^{57}$ Teachers could prompt increases in physical activity after children have been outdoors for a prolonged time either with active toys or teacher-led physical activity, which has 
been found to be a successful strategy. ${ }^{53}$ Indoors, there should be a continued focus on bridging educational and physical activity objectives, as done in some interventions. ${ }^{58,59}$ This is not intended to compete with other educational objectives but instead can facilitate a child's ability to learn. ${ }^{60,61}$

These data also show that small increases in the amount of physical activity in each classroom activity type could result in a large accumulation of daily MVPA. If an intervention was designed to increase MVPA in outdoor play, center time, and circle time by $10 \%$, MVPA would increase by 3.7 minutes daily or about 75 minutes monthly. Increasing MVPA by $10 \%$ would result in all, but 3 centers in our sample would meet recommendations. Alternatively, a $10 \%$ increase in average counts per minute would result in notable changes in energy expenditure. For example, for a 4-year-old female at the 50th percentile of body mass index $(16 \mathrm{~kg})$, a $10 \%$ increase in daily counts per minute would equate to an increase in daily caloric expenditure by 63 calories, which accumulates to more than 1250 calories per month. ${ }^{62}$ These increases are small but have been shown to be large enough to achieve the Healthy People 2020 goals. ${ }^{63}$

Future studies should work toward a more complete understanding of the role of physical activity within center-based care. Teacher-led physical activity is known to be an important contributor to children's overall physical activity levels and gross motor development, ${ }^{30,53}$ but more work is needed to understand how to support teachers in integrating structured physical activity into their schedules. Also, more research is needed on limiting seated time without hindering learning and developmental objectives. Currently, there is little understanding of how seated time is used within ECE settings and its impact on a child's overall physical activity levels and children's development. Our results show that children are required to be seated for nearly an hour each day, which may be detrimental to children's development and is important for future work to consider. Strengths of this study include the use of multiple, full-day, researcher-implemented observations in 49 centers and accelerometer-measured physical activity and sedentary behavior among 559 children.

Despite many strengths, several limitations of this study must be considered. One limitation is that some observation time could not be matched with accelerometer data. An average of 53 minutes per day was not categorized in the EPAO (Figure 1). This likely includes transitions between activities and infrequent activities, such as field trips (occurring on 3 observation days), but future research should aim to capture this information more formally. Also, activities not observed with a time stamp could not be matched with accelerometer data (eg, seated time, teacher-led physical activity). We have modified the observation to capture these activities with specific times so that the entire child-care day is better captured and can be fully linked with accelerometer data. The cross-sectional design of the study precludes the ability to draw causal inferences about the relationship between correlates and sedentary behavior or MVPA. Also, the data were collected between 2008 and 2009 and thus may not represent current practice; however, no major policy shifts have occurred at the state level around physical activity in ECE settings. Last, this study is limited in its representatives, as participating centers may be different than other North Carolina centers. However, more than half accepted tuition subsidies, that is, served lower income children, indicating representation from different socioeconomic groups. Centers in North Carolina may also be different from other places with different child-care regulations, geography, weather, and urbanization.

\section{Conclusions}

This study used objectively collected data from observations and accelerometry to understand the patterns of physical activity and sedentary behavior across the child-care day and the types of classroom activities that facilitated child physical activity. Children were observed as being more active outdoors and center time than other indoor activities (circle time and TV time). Results from this study reaffirm the tenants of organizations highlighting the importance of physical activity in ECE settings ${ }^{25}$ and highlight the potential opportunities for interventions focused on increasing physical activity and reducing sedentary behavior in preschoolers attending ECE centers.

\section{Acknowledgments}

Data for this study were collected through a grant from the Robert Wood Johnson Foundation, Healthy Eating Research, and Active Living Research programs. The content is solely the responsibility of the authors and does not necessarily represent the official views of the Robert Wood Johnson Foundation. The authors thank the ECE center directors, teachers, parents, and children for their participation.

\section{References}

1. Day RS, Fulton JE, Dai S, Mihalopoulos NL, Barradas DT. Nutrient intake, physical activity, and CVD risk factors in children: project HeartBeat! Am J Prev Med. 2009;37(suppl 1):S25-S33. doi:10.1016/ j.amepre.2009.04.006

2. Gidding SS, Barton BA, Dorgan JA, et al. Higher self-reported physical activity is associated with lower systolic blood pressure: the Dietary Intervention Study in Childhood (DISC). Pediatrics. 2006;118(6):2388-2393. PubMed doi:10.1542/peds.2006-1785

3. LeBlanc AG, Spence JC, Carson V, et al. Systematic review of sedentary behaviour and health indicators in the early years (aged 0-4 years). Appl Physiol Nutr Metab. 2012;37(4):753-772. PubMed doi:10.1139/h2012-063

4. Saakslahti A, Numminen P, Varstala V, et al. Physical activity as a preventive measure for coronary heart disease risk factors in early childhood. Scand J Med Sci Sports. 2004;14(3):143-149. PubMed doi:10.1111/j.1600-0838.2004.00347.x

5. Burgi F, Meyer U, Granacher U, et al. Relationship of physical activity with motor skills, aerobic fitness and body fat in preschool children: a cross-sectional and longitudinal study (Ballabeina). Int $J$ Obes. 2011;35(7):937-944. doi:10.1038/ijo.2011.54

6. Institute of Medicine. Early Childhood Obesity Prevention Policies. Washington, DC: The National Academies Press; 2011.

7. Koplan K, Liverman C, Kraak V, eds. Preventing Childhood Obesity: Health in the Balance. Washington, DC: Institute of Medicine, Committee on Prevention of Obesity in Children and Youth; 2005.

8. Moore LL, Gao D, Bradlee ML, et al. Does early physical activity predict body fat change throughout childhood? Prev Med. 2003;37(1): 10-17. PubMed doi:10.1016/S0091-7435(03)00048-3

9. Cliff DP, Okely AD, Smith LM, McKeen K. Relationships between fundamental movement skills and objectively measured physical activity in preschool children. Pediatr Exerc Sci. 2009;21(4):436449. PubMed doi:10.1123/pes.21.4.436

10. Fisher A, Reilly JJ, Kelly LA, et al. Fundamental movement skills and habitual physical activity in young children. Med Sci Sports Exerc. 2005;37(4):684-688. PubMed doi:10.1249/01.MSS.0000159138. 48107.7D 
11. Jones RA, Okely AD, Hinkley T, Batterham M, Burke C. Promoting gross motor skills and physical activity in childcare: a translational randomized controlled trial. J Sci Med Sport. 2016;19(9):744-749. PubMed doi:10.1016/j.jsams.2015.10.006

12. Wrotniak BH, Epstein LH, Dorn JM, Jones KE, Kondilis VA. The relationship between motor proficiency and physical activity in children. Pediatrics. 2006;118(6):e1758-e1765. PubMed doi:10. 1542/peds.2006-0742

13. Janz KF, Burns TL, Levy SM. Tracking of activity and sedentary behaviors in childhood: the Iowa Bone Development Study. Am J Prev Med. 2005;29(3):171-178. PubMed doi:10.1016/j.amepre.2005. 06.001

14. Janz KF, Burns TL, Torner JC, et al. Physical activity and bone measures in young children: the Iowa Bone Development Study. Pediatrics. 2001;107(6):1387-1393. PubMed doi:10.1542/peds. 107.6.1387

15. Specker B, Binkley T. Randomized trial of physical activity and calcium supplementation on bone mineral content in 3- to 5-year-old children. J Bone Miner Res. 2003;18(5):885-892. PubMed doi:10. 1359/jbmr.2003.18.5.885

16. Specker B, Binkley T, Fahrenwald N. Increased periosteal circumference remains present 12 months after an exercise intervention in preschool children. Bone. 2004;35(6):1389-1398. PubMed doi:10. 1016/j.bone.2004.09.005

17. Friedlander SL, Larkin EK, Rosen CL, Palermo TM, Redline S. Decreased quality of life associated with obesity in school-aged children. Arch Pediatr Adolesc Med. 2003;157(12):1206-1211. PubMed doi:10.1001/archpedi.157.12.1206

18. Hesketh K, Wake M, Waters E. Body mass index and parent-reported self-esteem in elementary school children: evidence for a causal relationship. Int J Obes Relat Metab Disord. 2004;28(10):12331237. doi:10.1038/sj.ijo.0802624

19. Krukowski RA, West DS, Philyaw Perez A, Bursac Z, Phillips MM, Raczynski JM. Overweight children, weight-based teasing and academic performance. Int J Pediatr Obes. 2009;4(4):274-280. PubMed doi:10.3109/17477160902846203

20. Zeller MH, Saelens BE, Roehrig H, Kirk S, Daniels SR. Psychological adjustment of obese youth presenting for weight management treatment. Obes Res. 2004;12(10):1576-1586. PubMed doi:10.1038/ oby.2004.197

21. Cohen AK, Rai M, Rehkopf DH, Abrams B. Educational attainment and obesity: a systematic review. Obes Rev. 2013;14:989-1005.

22. Datar A, Sturm R, Magnabosco JL. Childhood overweight and academic performance: national study of kindergartners and firstgraders. Obes Res. 2004;12(1):58-68. PubMed doi:10.1038/oby. 2004.9

23. Diamond A. Activities and programs that improve children's executive functions. Curr Dir Psychol Sci. 2012;21(5):335-341. PubMed doi:10.1177/0963721412453722

24. Larson N, Ward DS, Neelon SB, Story M. What role can child-care settings play in obesity prevention? A review of the evidence and call for research efforts. J Am Diet Assoc. 2011;111(9):1343-1362. PubMed doi:10.1016/j.jada.2011.06.007

25. National Physical Activity Plan Alliance. National Physical Activity Plan. 2016. http://www.physicalactivityplan.org/docs/2016NPAP_ Finalforwebsite.pdf. Accessed date January 4, 2017.

26. Story M, Kaphingst KM, French S. The role of child care settings in obesity prevention. Future Child. 2006;16(1):143-168. PubMed doi:10.1353/foc. 2006.0010

27. Mamedova S, Redford J. Early Childhood Program Participation, From the National Household Education Surveys Program of 2012 (NCES 2013-029). Washington, DC: National Center for Education
Statistics, Institute of Education Sciences, US Department of Education; 2013.

28. Iruka I, Carver P. Initial Results From the 2005 NEHS Early Childhood Program Participation Survey (NCES 2006075). Washington, DC: National Center for Education Statistics, Institute of Education Sciences, US Department of Education; 2006.

29. American Academy of Pediatrics, American Public Health Association, and National Resource Center for Health and Safety in Child Care and Early Education. Caring for Our Children: National Health and Safety Performance Standards; Guidelines for Early Care and Education Programs. Elk Grove Village, IL: American Academy of Pediatrics, American Public Health Association, National Resource Center for Health and Safety in Child Care and Early Education; 2011.

30. National Association for Sport and Physical Education. Active Start: A Statement of Physical Activity Guidelines for Children Birth to Five Years. 2nd ed. Reston, VA: National Association for Sport and Physical Education; 2009.

31. Beets MW, Bornstein D, Dowda M, Pate RR. Compliance with national guidelines for physical activity in U.S. preschoolers: measurement and interpretation. Pediatrics. 2011;127(4):658-664. PubMed doi:10.1542/peds.2010-2021

32. Hinkley T, Salmon J, Okely AD, Crawford D, Hesketh K. Preschoolers' physical activity, screen time, and compliance with recommendations. Med Sci Sports Exerc. 2012;44(3):458-465. PubMed doi:10. 1249/MSS.0b013e318233763b

33. Oliver M, Schofield GM, Kolt GS. Physical activity in preschoolers: understanding prevalence and measurement issues. Sports Med. 2007;37(12):1045-1070. PubMed doi:10.2165/00007256200737120-00004

34. Pate RR, O’Neill JR, Brown WH, Pfeiffer KA, Dowda M, Addy CL. Prevalence of compliance with a new physical activity guideline for preschool-age children. Child Obes. 2015;11(4):415-420. PubMed doi:10.1089/chi.2014.0143

35. Pate RR, Pfeiffer KA, Trost SG, Ziegler P, Dowda M. Physical activity among children attending preschools. Pediatrics. 2004;114(5): 1258-1263. PubMed doi:10.1542/peds.2003-1088-L

36. Reilly JJ. Low levels of objectively measured physical activity in preschoolers in child care. Med Sci Sports Exerc. 2010;42(3): 502-507. PubMed doi:10.1249/MSS.0b013e3181cea100

37. Bower JK, Hales DP, Tate DF, Rubin DA, Benjamin SE, Ward DS. The childcare environment and children's physical activity. Am J Prev Med. 2008;34(1):23-29. PubMed doi:10.1016/j.amepre.2007. 09.022

38. Dowda M, Brown WH, McIver KL, et al. Policies and characteristics of the preschool environment and physical activity of young children. Pediatrics. 2009;123(2):e261-e266. PubMed doi:10.1542/peds. 2008-2498

39. O'Neill JR, Pfeiffer KA, Dowda M, Pate RR. In-school and out-ofschool physical activity in preschool children. J Phys Act Health. 2016;13(6):606-610. doi:10.1123/jpah.2015-0245

40. Pate RR, O’Neill JR, Byun W, McIver KL, Dowda M, Brown WH. Physical activity in preschool children: comparison between Montessori and traditional preschools. J Sch Health. 2014;84(11): 716-721. PubMed doi:10.1111/josh.12207

41. Tandon PS, Saelens BE, Christakis DA. Active play opportunities at child care. Pediatrics. 2015;135(6):e1425-e1431. PubMed doi:10. 1542/peds.2014-2750

42. Ward DS, Mazzucca S, McWilliams C, Hales D. Use of the environment and policy evaluation and observation as a self-report instrument (EPAO-SR) to measure nutrition and physical activity environments in child care settings: validity and reliability evidence. Int $J$ 
Behav Nutr Phys Act. 2015;12:124. PubMed doi:10.1186/s12966015-0287-0

43. Ward D, Hales D, Haverly K, et al. An instrument to assess the obesogenic environment of child care centers. Am J Health Behav. 2008;32(4):380-386. PubMed doi:10.5993/AJHB.32.4.5

44. Benjamin Neelon SE, Taveras EM, Ostbye T, Gillman MW. Preventing obesity in infants and toddlers in child care: results from a pilot randomized controlled trial. Matern Child Health J. 2014; 18(5):1246-1257. PubMed doi:10.1007/s10995-013-1359-x

45. Gubbels JS, Kremers SP, van Kann DH, et al. Interaction between physical environment, social environment, and child characteristics in determining physical activity at child care. Health Psychol. 2011; 30(1):84-90. PubMed doi:10.1037/a0021586

46. Gubbels JS, Van Kann DH, Jansen MW. Play equipment, physical activity opportunities, and children's activity levels at childcare. $J$ Environ Public Health. 2012;2012:1-8. PubMed doi:10.1155/2012/ 326520

47. Lyn R, Maalouf J, Evers S, Davis J, Griffin M. Nutrition and physical activity in child care centers: the impact of a wellness policy initiative on Environment and Policy Assessment and Observation outcomes, 2011. Prev Chronic Dis. 2013;10:E83. PubMed doi:10.5888/pcd10. 120232

48. Tucker P, Vanderloo LM, Newnham-Kanas C, et al. Learning Environments' Activity Potential for Preschoolers (LEAPP): study rationale and design. J Public Health Res. 2013;2(2):19. PubMed doi:10.4081/jphr.2013.e19

49. Vanderloo LM, Tucker P, Johnson AM, van Zandvoort MM, Burke SM, Irwin JD. The influence of centre-based childcare on preschoolers' physical activity levels: a cross-sectional study. Int J Environ Res Public Health. 2014;11(2):1794-1802. PubMed doi:10.3390/ ijerph110201794

50. Troiano RP, Berrigan D, Dodd KW, Masse LC, Tilert T, McDowell M. Physical activity in the United States measured by accelerometer. Med Sci Sports Exerc. 2008;40(1):181-188. PubMed doi:10.1249/ mss.0b013e31815a51b3

51. Pate RR, Almeida MJ, McIver KL, Pfeiffer KA, Dowda M. Validation and calibration of an accelerometer in preschool children. Obesity. 2006;14(11):2000-2006. doi:10.1038/oby.2006.234

52. Evenson KR, Catellier DJ, Gill K, Ondrak KS, McMurray RG. Calibration of two objective measures of physical activity for children. J Sports Sci. 2008;26(14):1557-1565. PubMed doi:10.1080/ 02640410802334196
53. LaRowe TL, Tomayko EJ, Meinen AM, Hoiting J, Saxler C, Cullen B. Active early: one-year policy intervention to increase physical activity among early care and education programs in Wisconsin. BMC Public Health. 2016;16:607. PubMed doi:10.1186/s12889-0163198-3

54. Boldemann $\mathrm{C}$, Blennow $\mathrm{M}$, Dal $\mathrm{H}$, et al. Impact of preschool environment upon children's physical activity and sun exposure. Prev Med. 2006;42(4):301-308. PubMed doi:10.1016/j.ypmed. 2005.12.006

55. Olesen LG, Kristensen PL, Korsholm L, Froberg K. Physical activity in children attending preschools. Pediatrics. 2013;132(5):e1310e1318. PubMed doi:10.1542/peds.2012-3961

56. Cardon G, Van Cauwenberghe E, Labarque V, Haerens L, De Bourdeaudhuij I. The contribution of preschool playground factors in explaining children's physical activity during recess. Int J Behav Nutr Phys Act. 2008;5:11. PubMed doi:10.1186/1479-5868-5-11

57. Pate RR, Dowda M, Brown WH, Mitchell J, Addy C. Physical activity in preschool children with the transition to outdoors. $J$ Phys Act Health. 2013;10(2):170-175. PubMed doi:10.1123/jpah.10. 2.170

58. Pate RR, Brown WH, Pfeiffer KA, et al. An intervention to increase physical activity in children: a randomized controlled trial with 4year-olds in preschools. Am J Prev Med. 2016;51:12-22. PubMed doi:10.1016/j.amepre.2015.12.003

59. Trost SG, Fees B, Dzewaltowski D. Feasibility and efficacy of a "move and learn" physical activity curriculum in preschool children. $J$ Phys Act Health. 2008;5(1):88-103. PubMed doi:10.1123/jpah. 5.1.88

60. Pramling Samuelsson I, Johansson E. Play and learning - inseparable dimensions in preschool practice. Early Child Dev Care. 2006;176 (1):47-65. doi:10.1080/0300443042000302654

61. Samuelsson IP, Carlsson MA. The playing learning child: towards a pedagogy of early childhood. Scand J Educ Res. 2008;52(6):623641. doi:10.1080/00313830802497265

62. Trost SG, Pate RR, Sallis JF, et al. Age and gender differences in objectively measured physical activity in youth. Med Sci Sports Exerc. 2002;34(2):350-355. PubMed doi:10.1097/00005768200202000-00025

63. Wang YC, Orleans CT, Gortmaker SL. Reaching the healthy people goals for reducing childhood obesity: closing the energy gap. Am J Prev Med. 2012;42(5):437-444. PubMed doi:10.1016/j.amepre.2012. 01.018 